\title{
ANALYSES AND IMPLICATIONS OF THE ACCIDENTS IN THE SINGAPORE STRAIT
}

\author{
Xiaobo $\mathrm{Qu}^{1}$, Qiang Meng ${ }^{2}$, Suyi $\mathrm{Li}^{3}$ \\ ${ }^{1} \mathrm{PhD}$ candidate, ${ }^{2}$ Associate Professor \\ Department of Civil and Environmental Engineering \\ National University of Singapore \\ 10 Kent Ridge Crescent \\ Singapore 117576 \\ ${ }^{3}$ Research Assistant \\ Centre for Maritime Studies \\ National University of Singapore \\ 12 Prince George's Park \\ Singapore 118411
}

To the committee of Marine Safety and Human Factors (AW040) for review

Paper submitted to the $91^{\text {st }}$ Annual Meeting of Transportation Research Board to be considered for presentation and publication in Transportation Research Record

Total Number of Words

Number of words in text:

Number of tables: $\quad 0$

Number of figures: $\quad 3$

$=4643$ words

$0 \quad(0 \times 250) \quad=0 \quad$ words equivalent

Total number of words

$(3 \times 250)=750$ words equivalent

Corresponding author: Associate Professor Qiang Meng

Department of Civil Engineering

National University of Singapore

10 Kent Ridge Crescent

Singapore 117576

Email: ceemq@nus.edu.sg

Phone: +65-6516 5494

Fax: +65-6779 1635 


\begin{abstract}
This paper aims to estimate the lower and upper bounds of number of accidents occurred in the Singapore Strait over the past ten years on the basis of two maritime accident databases: Lloyd's List Intelligence (LLI) and Global Integrated Shipping Information System (GISIS). After analyzing incompleteness of these two data bases, a novel and tangible method is proposed to estimate the lower and upper bounds by using Bayesian analysis under the mild assumptions. The proposed method enables us to find the following three important results. Firstly, the annual maritime accident occurrence frequency in the Singapore Strait ranges from 17.6 to 33.0 , namely, only not more than $0.005 \%$ vessels could be involved in an accident when passing through the Strait. Secondly, the reporting performances of the two maritime accident databases are less than $62.5 \%$. In other words, more than $37.5 \%$ maritime accidents are not included in the database. Thirdly, ship collisions account for more than $50 \%$ out of all types of accidents, and it means that lowering down the occurrence of ship collision by enhancing the navigational systems in the Singapore Strait should put high priority.
\end{abstract}

Key words: Singapore Strait; Bayesian Analysis; Accident; Underreporting 


\section{INTRODUCTION}

The Straits of Malacca and Singapore is one of the most important shipping waterways in the world. It is the shortest shipping channel between the Indian Ocean and the Pacific Ocean, linking major economies such as Middle East, China, Japan and South Korea. There are around 300 vessels passing through the Straits on a daily basis and this gives an annual throughput of approximately 100,000 ships, carrying $80 \%$ of the oil transported to Northeast Asia as well as one third of the world's traded goods including Chinese manufactures, Indonesian coffee and etc. The Straits is not deep enough to accommodate some of the largest ships (mostly oil tankers). At Phillips Channel, the Straits narrows to 2.8 kilometres wide, with 2.1 kilometres in the shipping waterways, creating one of the world's traffic chokepoints. $\mathrm{Qu}$ and Meng (1) estimated that the direct daily loss of the Straits blockade to shippers and carriers is around 10 million US dollars. Apparently, the Straits is of great importance to the shippers, carriers, as well as global economy.

Major and minor disasters in the Straits have posed severe consequences, which may be caused by accidents due to the shallowness and narrowness of the Straits with high traffic volumes. The Joint War Committee (JWC) of Lloyd's Market Association (LMA) added the Straits of Malacca and Singapore to the list of high risk areas in 2005 (2). ${ }^{*}$ Several disastrous accidents, for example, the ship collision accident on Feb $1^{\text {st }}, 2008$, occurred in the Strait have raised the awareness among maritime authorities as well as researchers on the safety of navigation in the Straits. In October 2010, Maritime and Port Authority (MPA) of Singapore and the Joint Research Centre of the European Commission (EC) organised a workshop focusing navigational safety and container traffic security in the Singapore Strait. In the same month, at the $35^{\text {th }}$ meeting of the Tripartite Technical Experts Group on "The Safety of Navigation in the Straits of Malacca and Singapore" held at Yogyakarta of Indonesia, the Round Table of international shipping associations (RTisa) agreed with the three littoral states, (Indonesia, Malaysia, and Singapore) to initiate projects aimed at improving navigational safety within the Straits (3). Accordingly, a collaborative research project between National University of Singapore and MPA of Singapore was launched to develop a quantitative risk assessment (QRA) model for ship operations in the Strait.

The occurrence frequency of an accident is one of the most important contributing parameter in a QRA model $(4,5)$, and it can be estimated from historical accident records. The quality of the casualty data would thus have essential impact on the risk assessment and management of the Straits. Global Integrated Shipping Information System (GISIS) by International Maritime Organization (IMO) and Lloyd's List Intelligence (LLI) are two wellknown accident databases in the maritime industry and they can be used to estimate the frequency of accidents occurred in the Singapore Strait. The GISIS database includes the world wide maritime accident records with "serious casualties" or above reported by ship owners (6). By contrast, the LLI database collects all types of maritime accidents with different severities occurred worldwide of merchant vessels of more than 100 Gross Tonnage (GT). After a filtration analysis, we can find that the GISIS database reports 24 accidents with "serious casualties" or above and the LLI database contains 110 accident records occurred in the Singapore Strait from Jan 2001 to Jan 2011, 15 records of which are included by both databases. Although a severe accident happened on 11 February 2008 was reported by media, it was not included by either of these two databases. It can thus be concluded that these accident databases are incomplete to a certain extent. The possible reasons for the unreporting issue include oversight and deliberate withholding of information, local reporting procedures not known to the crew or ship owner, or companies' policy adverse to incident reporting due to fear for their reputations, etc. It is therefore of importance to put forward a tangible method so as to estimate the lower and upper bounds of the number of accidents occurred in the Singapore Strait using the available data.

The quality issue of accident data in road transport systems has been addressed extensively because it is worthwhile noting that underreporting of accident fatalities and injuries was identified between police and hospital records (7-11). A few researchers have

\footnotetext{
${ }^{*}$ It was subsequently listed out in the following year.
} 
recently drawn an attention to the maritime accident underreporting issue $(12,13)$. These studies aims to estimate the actual number of accidents (road traffic accidents or maritime accidents) on the basis of incomplete accident records obtained from different databases with the same sample space (all the occurred accident records). Three approaches are usually applied to estimate the actual number of accidents: the best case scenario method, the capturerecapture method, and the Bayesian conditional probability method. The best case scenario method is on the basis of assumption that all occurred accidents are reported to at least one database. This assumption does not hold for those maritime accidents happened in the Singapore Strait and recorded by either of the GISIS and LLI databases; for example, the accident record on 11 February 2008 was included in neither of these databases. The capturerecapture method originates from epidemiology and estimations of animal population sizes, and it assumes that the relevant data sources are independent (13). However, according to Psarros et al. (12), it is believed that the likelihood of a maritime accident being reported to one database is higher given that it has already been reported to another database, namely, the independent assumption on data sources does not hold for maritime accidents. The Bayesian condition probability method, however, could be used to estimate the lower bound of the number of maritime accidents (12). It should be pointed out that the Bayesian conditional probability method cannot be directly applied to analyze maritime accidents in Singapore Strait using either of the GISIS and LLI databases due to the reasons as follows. Firstly, focuses of these two maritime accident data bases are quite different. The GISIS reports only those accidents with high consequences ("serious casualties" or above), while LLI tries to cover all accidents with different severities (all the occurred accident records). This diversity causes significant difference on the sample spaces of these two databases. Secondly, the Bayesian conditional probability method can merely estimate a lower bound. In addition to a lower bound, a good upper bound estimation of maritime accident occurrence is utmost important to maritime authorities (e.g. MPA of Singapore) because an upper bound as the worst case can facilitate their decision-making process. Therefore, a new and tangible research methodology should be developed to estimate both lower and upper bounds of actual number of accidents occurred in the Singapore Strait by using two incomplete databases with different sample spaces: LLI and GISIS databases.

As the methodological contribution of this study, we will propose a Bayes' theorem based approach to estimate the lower and upper bounds using two incomplete databases with different sample spaces. The proposed methodology is able to estimate the maritime accident frequency in the Strait not only for maritime authorities but also for the public. The remainder of this paper is organized as follows. In the next section, data collected from the two sources are described and some preliminary results are presented. The maritime accident frequency estimation approach for the Singapore is subsequently elaborated. Based on the accident analyses, the implications are highlighted accordingly. The last section concludes this study.

\section{DATA DESCRIPTION}

\section{GISIS Database}

International Maritime Organization (IMO) classifies maritime accidents into three categories: very serious casualties, serious casualties, and others (less serious casualties and other marine accidents). Very serious casualties are casualties to ships which involve total loss of the ship, loss of life, or severe pollution. Serious casualties refer to casualties to ships which do not qualify as very serious casualties and which involve a fire, explosion, collision, grounding, contact, heavy weather damage, ice damage, hull cracking, or suspected hull defect, etc., resulting in immobilization of main engines, extensive accommodation damage, severe structural damage, pollution (regardless of quantity), or a breakdown necessitating towage or shore assistance. Less serious casualties and other marine accidents are casualties to ships which do not qualify as very serious casualties or serious casualties. According to IMO, in the event of an accident with serious casualties or very serious casualties, ship 
captains are suggested to submit a full investigation report to IMO within six months. Therefore, reported accidents with the categories of very serious casualties and serious casualties (represented by Type 1 accidents henceforth) are obtainable from the GISIS database. The sample space for GISIS database is all the Type 1 accidents occurred in the Strait. To retrieve the accident records occurred in the Singapore Strait, we use "Singapore", "Malaysia", "Malacca", and "Changi" as the key words to filter the irrelevant records. 29 records are obtained after the first round filtration. These records are manually checked to justify whether or not the accidents occurred in the Singapore Strait, and 24 Type 1 accidents occurred in the Strait from Jan 2001 to Jan 2011 are included in the database. Figure 1 depicts these 24 Type 1 accidents recorded by the GISIS database categorized by accident type.

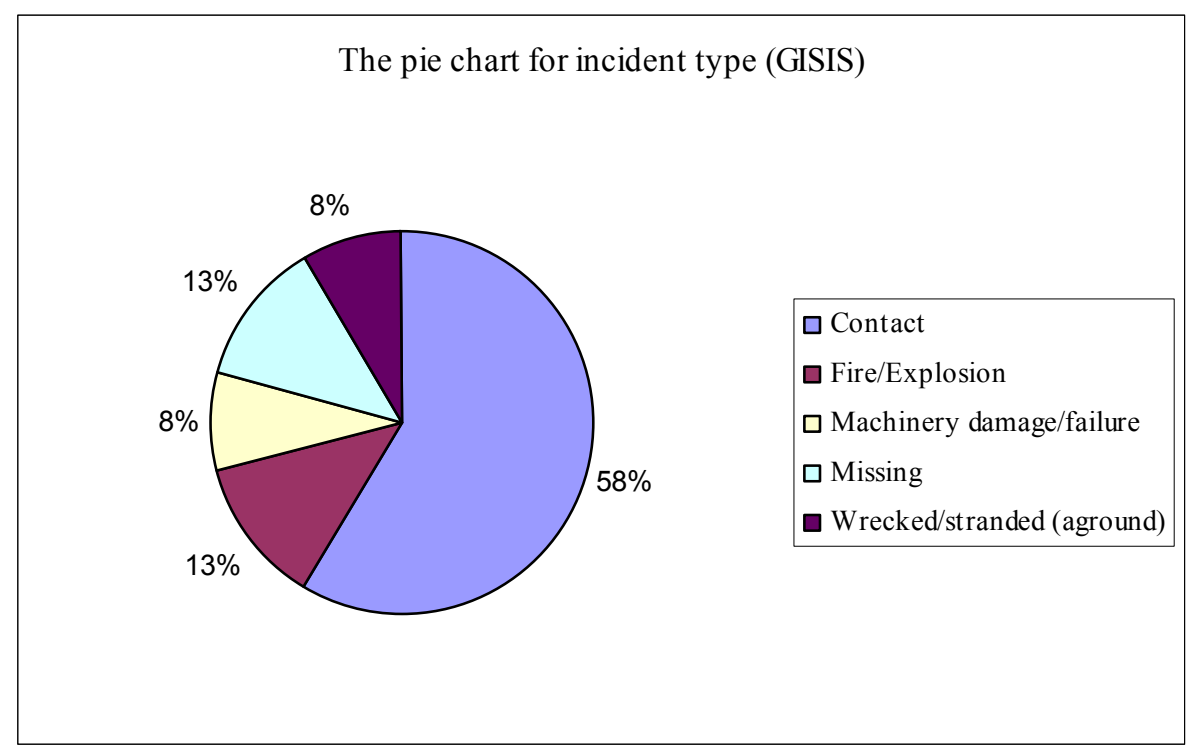

Figure 1: Pie chart for accident type (GISIS)

\section{LLI Casualty}

LLI casualty is a commercial database providing all types of maritime accident records occurred worldwide from Jan 2001 to Jan 2011 by Lloyd's List Intelligence. 25, 057 records are reported in the database. The sample space of this database refers to all types of maritime accidents, including Type 1 accidents and others (represented by Type 2 accidents henceforth). We use the same key words and filtration strategy to find the maritime accident records associated with Singapore Strait. 235 records are obtained after the first round filtration, out of which 110 accidents are identified to have occurred in the Singapore Straits (either in Traffic Separation Scheme lanes or in Singapore port waters) after second round check. Figure 2 illustrates distribution in terms of accident type of these 110 accidents 


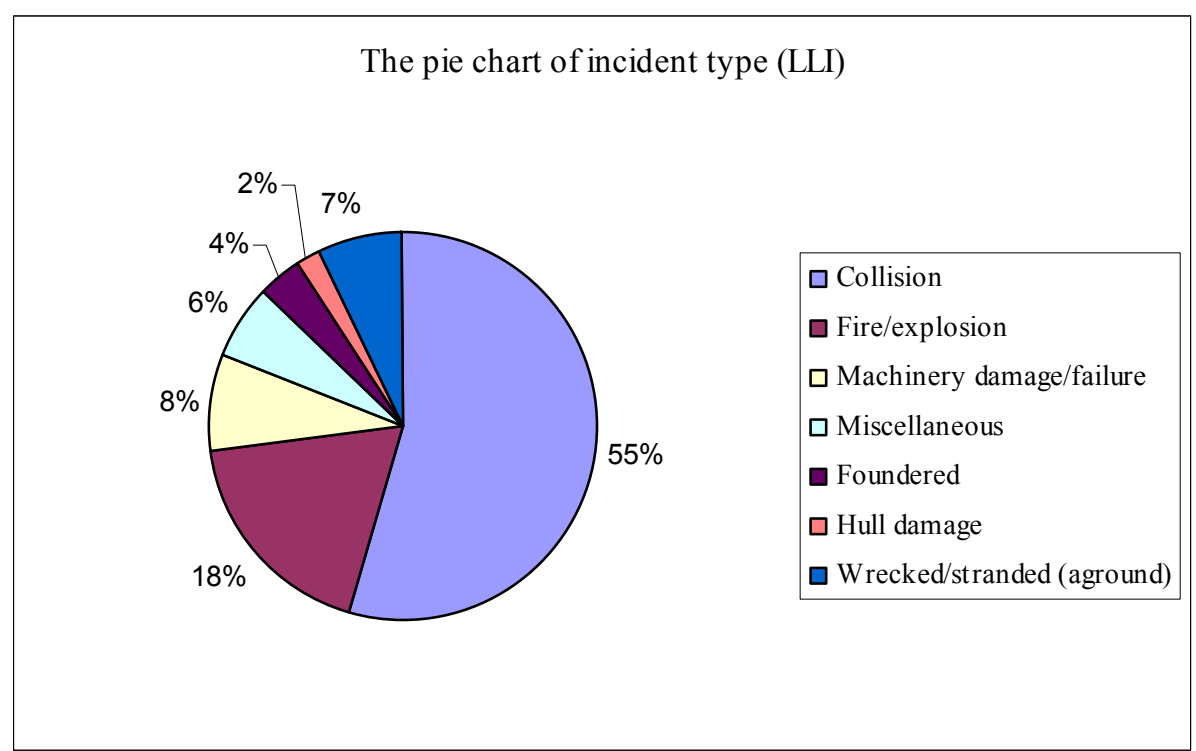

Figure 2: Pie chart of accident type (LLI)

\section{UNDERREPORTING ANALYSIS FOR THE ACCIDENTS IN THE STRAIT}

\section{Procedure and Notations}

As explained in the introductory section, the previous estimation approaches cannot be simply applied in this study due to the invalid assumptions and the issue of different sample spaces. Accordingly, in this section, a new approach is proposed to estimate the actual number of accidents occurred in the Singapore Strait using the two incomplete accident databases with different sample spaces (The sample space of GISIS database is all the Type 1 accidents and the sample space of LLI database is all types of accidents).

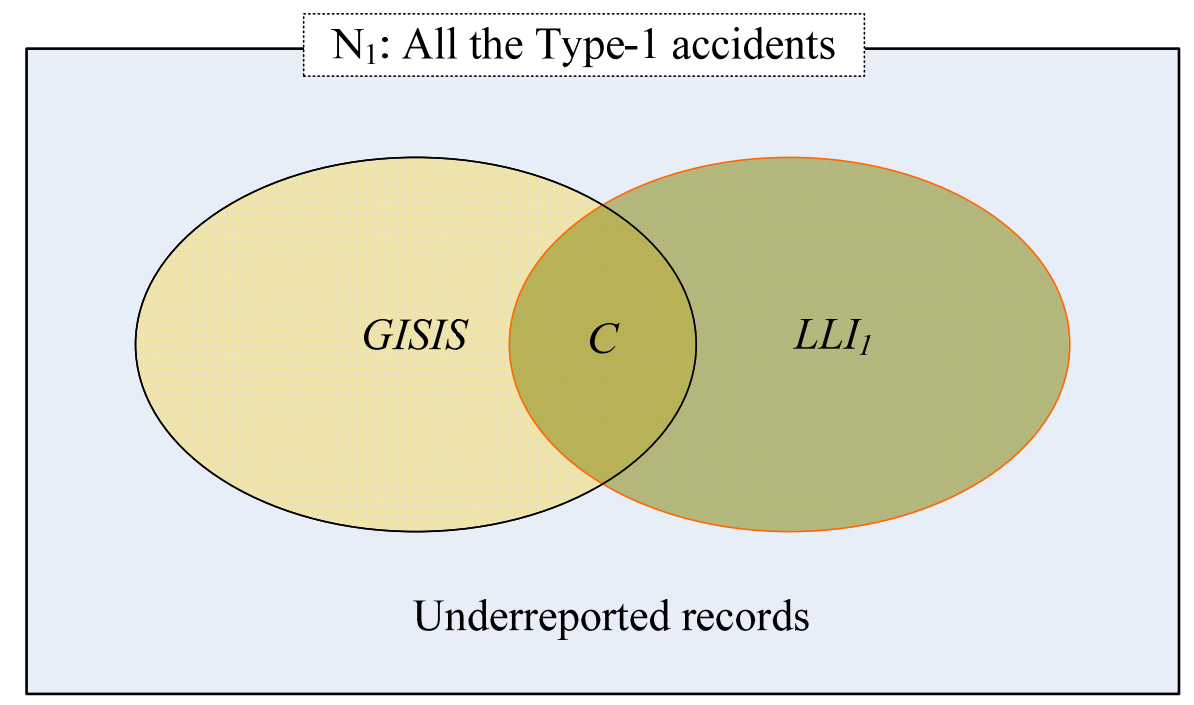

Figure 3: Sample space of Type-1 accidents

As can be seen in Figure 3, the two databases are subsets of the sample space of GISIS database - all the Type 1 accidents. The joint portion of the two databases is denoted as the set $C$. The reporting performance of a database refers to the ratio of the recorded accidents in the database out of the actual number of accidents (the whole sample space). It is assumed that the reporting performances of the $L L I$ database for the two types of accidents are the same in this study. The procedure of estimating the actual number of accidents is presented as follows: 
Step 1: (Category analysis) Classify all the 110 accidents recorded by the $L L I$ databases into two categories - Type 1 accidents and Type 2 accidents - in accordance with the detailed description of each accident record;

Step 2: (Reporting performance estimation) Estimate the lower and upper bounds of the reporting performance of the LLI database

Step 3: (number of accidents estimation) Estimate the lower and upper bounds of the actual number of accidents occurred in the Singapore Strait.

For the sake of presentation, the following notations are introduced for the subsequent discussion:

$$
N \text { : }
$$

$\bar{N}:$

$\underline{N}:$

$N_{i}$ :

$\bar{N}_{i}$ :

$\underline{N}_{i}:$

$|L L I|:$

$\left|L L I_{i}\right|:$

$|C|$ :

$P_{G}:$

$P_{L}$ :
Actual number of occurred accidents (i.e. number of accidents in the sample space of $L L I$ database);

Estimated upper bound of the actual number of occurred accidents;

Estimated lower bound of the actual number of occurred accidents;

Actual number of occurred accidents with Type $i$;

Estimated upper bound of the actual number of occurred accidents with Type $i$;

Estimated lower bound of the actual number of occurred accidents with Type $i$;

Number of accidents in the LLI database;

Number of accidents with Type $i$ in the LLI database;

Number of accidents recorded by both databases;

Reporting performance of the GISIS database;

Reporting performance of the LLI database;

$P\left(L L I_{1} \mid\right.$ GISIS $)$ : Conditional probability that an occurred Type 1 accident is included in the LLI database given that it has been covered by the GISIS database ${ }^{\dagger}$;

$P\left(G I S I S \mid L L I_{1}\right)$ : Conditional probability that an occurred Type 1 accident is included in the GISIS database given that it has been collected by LLI database;

$P\left(L L I_{1} \cap G I S I S\right)$ : Probability that an occurred Type 1 accident is included in both of the databases.

\section{Category Analysis and Reporting Performance Estimation Methodology}

The distinction on the sample spaces for the two databases makes us to further categorize the 110 accidents recorded in the LLI database by going through their detailed accident descriptions. According to the classifications defined by IMO, 4 accidents, 44 accidents, and 62 accidents are categorized as very serious casualties, serious casualties, and others, respectively. The number of Type 1 accidents recorded in the LLI database is 48 and the rest accidents are classified as the accidents with Type 2. It should be pointed out that all the 15 accidents recorded by both databases are Type 1 accidents.

We now estimate the lower and upper bounds of the LLI database' reporting performances. Two lower bounds are obtainable using the set theoretic operation and the Bayes' theorem, respectively; an upper bound can be calculated by analyzing importance and characteristics of the Singapore Strait. . According to Figure 3, it can be seen that the number of occurred Type 1 accidents, denoted by N, should be not less than cardinality of the union of the GISIS and $L L I_{l}$ databases, namely:

\footnotetext{
${ }^{\dagger}$ Type- 2 accidents would not be possible to be recorded by GISIS database.
} 


$$
N_{1} \geq\left(\left|L L I_{1}\right|+\mid \text { GISIS } \mid\right)-|C|
$$

The first lower bound of the LLI database' reporting performance can be derived using the right hand side of eqn. (1).

Since $P\left(L L I_{1} \mid\right.$ GISIS $)$ is the conditional probability that an occurred Type 1 accident is included in the LLI database in the condition that it has been covered by the GISIS database, it can be approximated by

$$
P\left(L L I_{1} \cap \text { GISIS }\right) \approx \frac{|C|}{N_{1}}
$$

According to the assumption that the reporting performances of the $L L I$ database for the two types of accidents are the same, the reporting performance of the LLI database can be calculated below:

$$
P_{L} \approx \frac{\left|L L I_{1}\right|}{N_{1}} \approx \frac{\left|L L I_{2}\right|}{N_{2}} \approx \frac{|L L I|}{N}
$$

The reporting performance of the GISIS database can be estimated by

$$
P_{G} \approx \frac{|G I S I S|}{N_{1}}
$$

According to the classical the Bayes' theorem, it follows that

$$
P\left(L L I_{1} \cap G I S I S\right)=P\left(L L I_{1} \mid G I S I S\right) \times P_{G}=P\left(G I S I S \mid L L I_{1}\right) \times P_{L}
$$

It is believed that the likelihood of an accident being reported to the LLI database is higher given that it has been reported to GISIS (and vice versa), namely,

$$
\begin{aligned}
& P\left(L L I_{1} \mid G I S I S\right) \geq P_{L} \\
& P\left(\text { GISIS } \mid L L I_{1}\right) \geq P_{G}
\end{aligned}
$$

Substituting eqns. (6) and (7) into to eqn. (5) yields that

$$
P\left(L L I_{1} \cap G I S I S\right) \geq P_{L} P_{G}
$$

Eqns. (2)-(4) implies that

$$
\frac{|C|}{N_{1}} \geq \frac{\left|L L I_{1}\right|}{N_{1}} \times \frac{|G I S I S|}{N_{1}}
$$

Eqn. (9) contributes the second lower bound of the actual number of occurred Type 1 as follows.

$$
N_{1} \geq \frac{|G I S I S| \times\left|L L I_{1}\right|}{|C|}
$$

The following proposition demonstrates that the second lower bound is tighter than the first lower bound:

Proposition: The second lower bound shown in the right hand side of eqn. (10) is not less than the first lower bound shown in the right hand side of eqn. (1), namely:

$$
\frac{|G I S I S| \times\left|L L I_{1}\right|}{|C|} \geq\left(\left|L L I_{1}\right|+\mid \text { GISIS } \mid\right)-|C|
$$

Proof: Since the cardinality of the intersection of the GISIS and $L L I_{1}$ databases cannot exceed the cardinality of the GISIS or $L L I_{l}$ database, we have

$$
\begin{aligned}
& \mid \text { GISIS } \mid \geq C \\
& \left|L L I_{1}\right| \geq|C|
\end{aligned}
$$

Eqns. (12)-(13) implies that

$$
(|G I S I S|-|C|) \times\left(\left|L L I_{1}\right|-|C|\right) \geq 0
$$

Adding $\left(\left|L L I_{1}\right|-|C|\right) \times|C|+|C|^{2}+(\mid$ GISIS $|-| C \mid) \times|C|$ to both sides of eqn. (14) yields that 
After simplifying both sides of eqn. (15), we obtain the inequality:

$$
\mid \text { GISIS }|\times| L L I|\geq| C \mid \times\left(\left|L L I_{1}\right|+\mid \text { GISIS }|-| C \mid\right)
$$

Eqn. (16) can be rewritten as follows:

$$
\frac{|G I S I S| \times\left|L L I_{1}\right|}{|C|} \geq\left(\left|L L I_{1}\right|+|G I S I S|\right)-|C|
$$

The proof is completed.

The above proposition enables us to estimate a good lower bound of the actual number of accidents with type 1 occurred in Singapore Strait as follows:

$$
\underline{N}_{1}=\max \left\{\frac{|G I S I S| \times\left|L L I_{1}\right|}{|C|},|G I S I S|+\left|L L I_{1}\right|-|C|\right\}=\frac{|G I S I S| \times\left|L L I_{1}\right|}{|C|}=76.8
$$

According to the assumption that the reporting performance of the $L L I$ database are the same for Type 1 and Type 2 accidents, the upper bound of the reporting rate of the $L L I$ database could be computed by

$$
\bar{P}_{L}=\frac{\left|L L I_{1}\right|}{\underline{N}_{1}}=\frac{48}{76.8}=62.5 \%
$$

Since 1998, the International Maritime Organization (IMO) adopted the mandatory ship reporting system in the Straits of Malacca and Singapore that was proposed by the three littoral countries including Indonesia, Malaysia, and Singapore. According to the system, the Singapore Strait is under the authority of Singapore Vessel Traffic Services (VTS) centre. In addition, the MPA of Singapore has put in place a comprehensive system to response any maritime emergency or accident. More importantly, due to the economic importance of the Strait, some high profile accidents would definitely attract significant media coverage and thus facilitate the administrators of the databases to attain the data records. Consequently, it is safe to say that the reporting rates of accidents occurred in the Singapore Strait are at least above the average level. According to Psarros et al. (12), around one in three occurred accidents are reported in the $L L I$ database. Hence, the reporting rate of LLI database for the accidents occurred in the Singapore is at least $1 / 3$, represented by

$$
\underline{P}_{L}=33.3 \%
$$

As per eqns. (18)-(19), the reporting performance of the LLI database is within the range of $[33.3 \%, 62.5 \%]$. Therefore, the actual number of accidents should be between 176 and 330 .

\section{IMPLICATIONS AND DISCUSSIONS}

The accident frequency in the Singapore Strait is approximately 17.6 to 33.0 cases per year. Based on the statistics by MPA of Singapore, the annual traffic volume of the Strait in 2010 is around $1,200,000$ vessels. Thus, only not more than $0.005 \%$ vessels are involved in accidents with different severities. Accordingly, as of now, the Strait could be considered as a safe shipping channel. However, according to the review of maritime transport 2008 published by the United Nations Conference on Trade and Development, global maritime trade is predicted to increase by $44 \%$ in 2020 and double by 2031 (14). By then, the accident rate would be much higher and new risk reduction solutions should be proposed and implemented.

The underreporting has been of great concern of maritime and port authorities. From the analyses above, it can be seen that the reporting performances of the databases are not good $(<62.5 \%)$. A significant portion of accidents are misreported due to various reasons. Accordingly, a systematic mandatory accident reporting system is of great necessity to grasp a complete picture of the operational status of the Strait. 
Ship collisions constitute more than $50 \%$ out of various severities of accidents, which would be considered as the most frequent accident types occurred in the Strait. In reality, various systems have already been implemented aiming at lowering down the frequency of ship collisions. For example, the Traffic Separation Scheme (TSS) was brought into force on 1 May 1981 for safer navigation in the Straits of Malacca and Singapore. Since then, the opposing streams of traffic have been separated by the establishment of traffic lanes. In 1998, the International Maritime Organization (IMO) adopted the mandatory ship reporting system in the Straits of Malacca and Singapore that was proposed by the three littoral countries (15). Furthermore, in 1998, the Society of International Gas Tanker and Terminal Operators Ltd (SIGTTO) published the $1^{\text {st }}$ version of Passage Planning Guide: Malacca \& Singapore Straits, including the Straits background and passage notes, to provide guidance of ship masters and navigating officers transiting the Straits (16). However, to date, the frequency of collisions is still becoming higher year by year due to the increasing traffic volume. More attention and efforts should be paid to the issue of ship collisions.

\section{CONCLUSIONS}

This paper aims to estimate the lower and upper bounds of number of accidents occurred in the Singapore Strait over the past ten years on the basis of two maritime accident databases: Lloyd's List Intelligence (LLI) and Global Integrated Shipping Information System (GISIS). After analyzing incompleteness of these two data bases, a novel and tangible method is proposed to estimate the lower and upper bounds by using Bayesian analysis under the mild assumptions. The proposed method enables us to find the following three important results. Firstly, the annual maritime accident occurrence frequency in the Singapore Strait ranges from 17.6 to 33.0 , namely, only not more than $0.005 \%$ vessels could be involved in an accident when passing through the Strait. Secondly, the reporting performances of the two maritime accident databases are less than $62.5 \%$. In other words, more than $37.5 \%$ maritime accidents are not included in the database. Thirdly, ship collisions accounts for more than $50 \%$ out of all types of accidents, and it means that lowering down the occurrence of ship collision by enhancing the navigational systems in the Singapore Strait should put high priority.

\section{ACKNOWLEDGEMENTS}

This study is part of the research project "Development of QRA model and software for shipping operations in the Straits of Malacca and Singapore" funded by Maritime Innovation and Technology Fund of Singapore (WBS No. R-264-000-281-490 and R-702-000-004-490).

\section{REFERENCES}

1. Qu, X., and Q. Meng. The economic importance of the Straits of Malacca and Singapore: An extreme-scenario analysis. Transportation Research Part E: Logistics and Transportation Review. Vol. 48, 2012, pp. 258-265.

2. Thomas, B. Malacca Strait a "war risk zone"? Lloyd's should review its assessment. IDSS Commentaries (57), 2005. http://dr.ntu.edu.sg/bitstream/handle/10220/4137/RSISCOMMENT 293.pdf Assessed July 16th, 2011.

3. RTisa. The Safety of Navigation in the Straits of Malacca and Singapore. The round table of international shipping associations (RTisa), Yogyakarta, Indonesia, 4-7 Oct 2010.

4. Meng Q., X. Qu, X. Wang, Y. Vivi, and S.C. Wong. Quantitative risk assessment modeling for non-homogeneous urban road tunnels. Risk Analysis. Vol. 31, 2011, pp. 382-403.

5. Meng Q., X. Qu, K.T. Yong, and Y.H. Wong. QRA model based risk impact analysis of traffic flow in urban road tunnels. Published online ahead of print. Risk Analysis. 2011. DOI: $10.1111 / \mathrm{j} .1539-6924.2011 .01624 . x$ 
6. IMO, Global Integrated Shipping Information System. http://gisis.imo.org/Public/ Accessed 16 July 2011.

7. Alsop, J., and J. Langley. Under-reporting of motor vehicle traffic crash victims in New Zealand. Accident Analysis and Prevention. Vol. 33, 2001, pp. 353-359.

8. Sciortino, S., M. Vassar, M. Radetskya, and M.M. Knudson. San Francisco pedestrian injury surveillance: mapping, under-reporting, and injury severity in police and hospital records. Accident Analysis and Prevention. Vol. 37, 2005, pp. 1102-1113.

9. Amoros, E., J.L. Martin, B. Laumon. Under-reporting of road crash casualties in France. Accident Analysis and Prevention. Vol. 38, 2006, pp. 627-635.

10. Aptel, I., L.R. Salmi, F. Masson, A. Bourdé, G. Henrion, and P. Erny. Road accident statistics: discrepancies between police and hospital data in a French island. Accident Analysis \& Prevention, Vol. 31, 1999, pp. 101-108.

11. Elvik, R., A.B. Mysen. Incomplete accident reporting: meta-analysis of studies made in 13 countries. In Transportation Research Record: Journal of the Transportation Research Board, No. 1665, Transportation Research Board of the National Academies, Washington, D.C., 1999, pp. 133-140.

12. Psarros, G., R. Skjong, and M.S. Eide. Under-reporting of maritime accidents. Accident Analysis and Prevention, Vol. 42, 2010, pp. 619-625.

13. Hassel, M. Underreporting of maritime accidents to vessel accident databases. Accident Analysis and Prevention. 2011. Published online ahead of print. doi: 10.1016/j.aap.2011.05.027

14. UNCTAD. (2008) Review of Maritime Transport 2008. http://www.unctad.org/Templates/WebFlyer.asp?intItemID=4659\&lang=1 Accessed on 19 July 2011.

15. Maritime and Port Authority of Singapore. Straits Reporting System. 2010. http://www.mpa.gov.sg/sites/port_and_shipping/port/vessel_traffic_information_system(vt is)/straitrep/straitrep.page Accessed on 19 July 2011.

16. SIGTTO. Passage Planning Guide: Malacca \& Singapore Straits (2nd Edition 2008). Witherby Seamanship International Ltd., 2008. 